\title{
Epstein-Barr Virus, the Virome, and the 'Biography' of the Immune System
}

\author{
Krone $\mathrm{B}^{1,2 *}$, Grange JM${ }^{3}$ \\ ${ }^{1}$ Center for Hygiene and Human Genetics, University of Göttingen, Germany \\ ${ }^{2}$ Medical Laboratory, Kurt-Reuber-Haus, Kassel, Germany \\ ${ }^{3}$ Immodulon Therapeutics, London, UK
}

\section{Letter to Editor}

A recently published monograph on Epstein-Barr virus (EBV), subtitled 'one herpes virus, many diseases' contains a wealth of information on this virus and its roles in human disease, with particular emphasis on multiple sclerosis (MS) and malignant diseases such as nasopharyngeal carcinoma and Hodgkin lymphoma [1], as well as infectious mononucleosis which is usually a self-limiting disease without permanent complications. As EBV causes a range of serious diseases, the question is raised whether contemporary techniques for vaccine development might be used to prepare prophylactic and, perhaps, immunotherapeutic agents for at least some of these diseases. The experimental vaccines currently available cannot, however, prevent infection with wild strains of EBV [2]. An evaluation of possible vaccination strategies requires consideration of two factors that have, to date, received little or no attention. First, EBV is an almost universal and strongly immunogenic member of the human microbiome/virome [3-5] and, second, a concept termed 'the biography of the immune system' can play a key role in the way how parts of the immune response become directed and how acquired or endogenous microorganisms/viruses are subsequently handled by the host $[6,7]$. It is thus increasingly recognised that the ability of the individual immune system to fight infecting microorganisms and to take part in cancer immune surveillance is highly dependent on the population of endogenous micro-organisms including viruses (the microbiome and virome) and the past history, or 'biography', of the host immune system [8]. Linear and non-linear interactions between different co-players of the microbiome/virome, including human endogenous retroviruses, have been described [9]. Moreover, various micro-organisms/viruses, are obviously able to substitute for each other, at least in part, in their roles in the microbiome/virome so that the disappearance of a given immunogenic member might not become of relevance until in combination with accumulating disappearances of other permanent or transient co-players [7]. EBV is present in all human communities, including the industrialized countries where infection increasingly occurs in adolescents and young adults rather than soon after birth. Worldwide, the EBV sero-prevalence is high (>95\%) so a permanent absence of this virus would be extremely uncommon with regard to the long co-evolution with humans and the consequences of this have, until now, not been considered. Certainly a delay in the timing of infection can have adverse consequences and, in this respect, observational studies strongly suggest that a predisposition for MS can result when a primary infection with EBV is delayed until teen-age or early adulthood [10]. It has been hypothesised that EBV can cause a

subversion of a MS-protective immune reaction which, once subverted or eclipsed, is not easily repaired. An explanation has been given based on the phenomenon of 'original antigenic sin' and candidate epitopes on the viral EBNA1 protein have been delineated [6]. In general, however, a causative role of EBV for MS is still not definitively proven and there are also more direct role(s) for EBV in the pathogenesis of MS under consideration [11]. Although much more work needs to be done on the virus-host interactions following EBV infection it is increasingly apparent that such studies will need to take into account the overall composition of the virome as well as the 'biography' of the immune system, both of which could have far reaching consequences on the outcome of the infection or immunological significant contact. These considerations lead to the view that the use of a living attenuated vaccine given in early childhood would be far preferable to the use of sub-unit vaccines to be given irrespective of age at vaccination. Other types of agents might, however, be appropriate for the immunotherapy of any established EBV related disease.

\section{References}

1. Münz C (2015) Epstein Barr Virus. Vol 1 and 2 Curr Topics Microbiol Immunol: 390 391.

2. Smith C, Khanna R (2015) The Development of Prophylactic and Therapeutic EBV Vaccines. Curr Top Microbiol Immunol 391: 455-473. [Crossref]

3. Integrative HMP (iHMP) Research Network Consortium (2014) The integrative human microbiome project: dynamic analysis of microbiome-host omics profiles during periods of human health and disease. Cell Host Microbe 16: 276-289. [Crossref]

4. Virgin HW (2014) The virome in mammalian physiology and disease. Cell 157: 142150. [Crossref]

5. Wylie KM, Weinstock GM, Storch GA (2013) Virome genomics: a tool for defining the human virome. Curr Opin Microbiol 16: 479-484. [Crossref]

6. Krone B, Oeffner F, Grange JM (2009) Is the risk of multiple sclerosis related to the 'biography' of the immune system? J Neurol 256: 1052-1060. [Crossref]

7. Krone B, Kölmel KF, Grange JM (2014) The biography of the immune system and the control of cancer: from St Peregrine to contemporary vaccination strategies. $B M C$ Cancer 14: 595. [Crossref]

8. Muraille E (2015) The unspecific side of acquired immunity against infectious disease: cause and consequences. Front Microbiol 6: 1525.

Correspondence to: Krone B, Medical Laboratory, Kurt-Reuber-Haus, Herkulesstraße 34a, 34119 Kassel, Germany, Tel: +49 551 56440, Fax: + 49561 9188109; E-mail: Bernd-Krone@t-online.de

Received: December 02, 2015; Accepted: December 21, 2015; Published: December 23, 2015 
9. Wang W, Jovel J, Halloran B, Wine E, Patterson J, et al. (2015) Metagenomic analysis of microbiome in colon tissue from subjects with inflammatory bowel diseases reveals interplay of viruses and bacteria. Inflamm Bowel Dis 21: 1419-1427. [Crossref]

10. Ascherio A, Munger KL (2015) EBV and Autoimmunity. Curr Top Microbiol Immunol 390: 365-385. [Crossref]
11. Lassmann H, Niedobitek G, Aloisi F, Middeldorp JM; NeuroproMiSe EBV Working Group (2011) Epstein-Barr virus in the multiple sclerosis brain: a controversial issue-report on a focused workshop held in the Centre for Brain Research of the Medical University of Vienna, Austria. Brain 134: 2772-2786. [Crossref]

Copyright: (C2015 Krone B. This is an open-access article distributed under the terms of the Creative Commons Attribution License, which permits unrestricted use, distribution, and reproduction in any medium, provided the original author and source are credited. 